\title{
Direitos da Personalidade das Mulheres Sob a Perspectiva da Dignidade da Pessoa Humana como Axioma Justificante
}

\begin{abstract}
Dirceu Pereira Siqueira
Coordenador e professor permanente do Programa de Doutorado e Mestrado em Direito do Centro Universitário Cesumar (UniCesumar). Pós-Doutorado em Direito pela Faculdade de Direito da Universidade de Coimbra (Portugal). Doutorado e Mestrado em Direito Constitucional pela Instituição Toledo de Ensino (ITE/Bauru). Especialização em Direito Civil e Processual Civil pelo Centro Universitário de Rio Preto. Pesquisador bolsista - Modalidade Produtividade em Pesquisa para Doutor (PPD), do Instituto Cesumar de Ciência, Tecnologia e Inovação (Iceti). Professor nos cursos de Graduação em Direito da Universidade de Araraquara (Uniara), do Centro Universitário Unifafibe e do Centro Universitário da Fundação Educacional de Barretos (Unifeb). Professor convidado do Programa de Mestrado em "Gestão Estratégica de Empresas - Master of Science in Administrative Studies (MSAS)" - University Missouri State - EUA. Editor-chefe da Revista Direitos Sociais e Políticas Públicas (Qualis B1). Consultor jurídico. Advogado. http://lattes.cnpq.br/3134794995883683. https://orcid.org/0000-0001-9073-7759. dpsiqueira@uol.com.br
\end{abstract}

\section{Sabrina Medina Andrecioli}

Bacharel em direito pela Universidade Estadual de Maringá. Especialista em Direito Aplicado pela Escola da Magistratura do Paraná. Mestre em Ciências Jurídicas- Direitos da Personalidade e seu Alcance na Contemporaneidade do Programa de Pós-Graduação em Ciências Jurídicas Mestrado da UniCesumar. Graduanda em Letras - Português/Inglês pela UniCesumar. Pós-graduanda em Docência em Ensino

Superior: Tecnologias Educacionais e Inovação pela UniCesumar. Professora de Direito de graduação e pós-graduação. Advogada. http://lattes.cnpq.br/2263740228017008. https://orcid.org/0000-0001-9230-0083. sah_andri@hotmail.com

A sociedade plural atual impõe ao Direito inovações em suas reflexões e respostas a temas que atingem a existência humana. Diante de um cenário de grande violência e violações de direitos, que as mulheres ainda vivenciam na atualidade, é que se constata a real importância de se tratar da temática e dos direitos humanos dessa parcela da população. Verifica-se que a atual estrutura social continua a basear-se num modelo patriarcal no qual persistem papéis e estereótipos que colocam as mulheres numa posição claramente inferior em relação aos homens e que, portanto, criou uma situação de discriminação contra as mulheres em razão do seu gênero. A vulnerabilidade levou a situações de abuso de poder e inclusive a situações que transcendem a esfera privada, abrangendo também a esfera pública do indivíduo. Esta realidade social, na qual a verdadeira igualdade tem se destacado pela sua ausência, foi fomentada pela falta de uma cultura jurídica sobre os direitos humanos das mulheres. Este trabalho tem por objetivo, portanto, a análise da evolução dos direitos humanos e do seu caráter universal, bem como o levantamento dos instrumentos internacionais de proteção dos direitos da mulher e suas especificidades na busca da efetividade dos direitos humanos. Empregou-se, para tanto, o método dedutivo de abordagem e o método funcional de procedimento, e, quanto aos métodos de investigação, utilizou-se o bibliográfico e o documental.

Palavras-chave: Direitos da personalidade. Direitos humanos. Dignidade da pessoa humana. Mulheres.

\section{RIGHTS PERSONALITY OF WOMEN UNDER THE PERSPECTIVE OF HUMAN DIGNITY AS A JUSTIFICANT AXIOMA}

Oday's plural society imposes innovations on law in its reflections and responses to themes that affect human existence. Faced with a scenario of great violence and violations of rights, which women still experience today, is the real importance of addressing the issue and human rights of this portion of the population. It appears that the current social structure continues to be based on a patriarchal model in which roles and stereotypes persist that place women in a significantly lower position than men and therefore created discrimination against women because of their gender. genre. Vulnerability has led to situations of abuse of power and even situations that transcend the private sphere, also encompassing the public sphere of the individual. This social reality, in which true equality has been highlighted by its absence, has been fostered by the absence of a legal culture on women's human rights. Therefore, this paper aims to analyze the evolution of human rights and their universal character, as well as the survey of international instruments for the protection of women's rights, and their specificities in the pursuit of the effectiveness of human rights. The deductive method of approach, the functional method of procedure and the research methods were used for bibliographic and documentary.

Keywords: Personality rights. Human rights. Dignity of human person. Women.

\section{SUMÁRIO}

1 Introdução. 2 Direitos humanos e a dignidade da pessoa humana. 3 Da universalidade dos direitos humanos. 4 Os direitos humanos e as mulheres. 4.1 Dos instrumentos de proteção internacionais dos direitos das mulheres. 5 Considerações finais. 6 Referências. 


\section{Humanos e \\ Democracia}

\section{INTRODUÇÃO}

Em pleno século 21, apesar de existirem instrumentos jurídicos e sistemas de garantia destinados à proteção dos direitos humanos das mulheres, verificam-se casos e fatos de muita violação e agressão à dignidade humana das mulheres, desrespeitando seus direitos mais fundamentais.

Mulheres em todo o mundo sofrem violência física, emocional, econômica, sexual, verbal, psicológica ou simbólica. $\mathrm{O}$ atraso na integração da perspectiva de gênero no direito internacional dos direitos humanos dificultou a obtenção de uma igualdade real entre homens e mulheres; e isso, apesar do princípio de igualdade aparecer nos principais tratados sobre direitos humanos, o reconhecimento à igualdade formal não garante essa igualdade real.

Diante de um cenário de invisibilidade, violência e descaso, em que estão inseridas as mulheres, o presente trabalho tem como finalidade promover reflexões sobre o sistema de direitos humanos e seus instrumentos de proteção. Para tanto, fixa o princípio da dignidade da pessoa humana como cláusula geral de proteção da pessoa.

A propagação das normas de proteção aos direitos humanos das mulheres assume papel fundamental enquanto propulsora de mudanças no campo de valores, restando indispensável revisitar o contexto sociocultural, calcado na assimetria de poder entre homens e muIheres.

É importante trabalhar a temática direitos humanos, a concepção de evolução histórica e os efeitos após as duas grandes guerras, diante da concepção da dignidade da pessoa humana como axioma dos direitos humanos e fundamentais.

Desta forma, o objetivo deste estudo será o de oferecer uma visão geral sobre os direitos humanos, sua evolução histórica e seu caráter universal, bem como verificar os instrumentos jurídicos internacionais que garantem os direitos das mulheres e suas efetividades. Assim, o que se espera é que as informações apresentadas possam contribuir para uma reflexão mais profunda sobre os direitos humanos das mulheres.

Utiliza-se o método de abordagem dedutivo, partindo de teorias gerais para a ocorrência de fenômenos particulares, na busca do derradeiro objetivo representado na identificação do sujeito objeto do estudo e seus direitos, sendo realizada uma análise reflexiva. Já como método de procedimento, utiliza-se o casuístico e o funcional, consistindo em analisar o todo do ponto de vista da função de suas unidades. Por fim, quanto aos métodos de investigação, emprega-se o bibliográfico e o documental, realizado por meio de consulta de obras, artigos de periódicos e documentos eletrônicos e internacionais.

Para tanto, o estudo foi dividido em três tópicos. No primeiro, irá contextualizar e trazer conceituações sobre a temática direitos humanos de uma forma mais ampla, por meio da análise da evolução histórica de tais direitos, bem como breve exame da Dignidade da Pessoa Humana como núcleo fundante dos direitos do homem.

No segundo tópico, far-se-á um exame acerca da universalidade dos direitos do homem, quando se levanta o dilema da propositura de direitos humanos universais ante a diversidade cultural. Neste tópico discute-se, também, sobre a correlação do processo de globalização com a crise de legitimidade das políticas de direitos humanos vivenciada na era contemporânea. 
Por fim, a terceira parte investigará os direitos humanos referentes à mulher, ou seja, serão analisados os instrumentos jurídicos existentes no contexto internacional para lutar contra este tipo de discriminação e violação de direitos referente às mulheres.

\section{DIREITOS HUMANOS E A DIGNIDADE DA PESSOA HUMANA}

Por meio de uma perspectiva contemporânea, pode-se inferir que os direitos humanos são conquistas construídas historicamente ao longo de uma jornada existencial complexa, com diversos momentos de escassez em todos os sentidos, e em alguns de abundância restrita, não novidade na seara do direito. Assim, faz-se necessário analisar tal processo de conquistas históricas dos homens.

O homem está em constante evolução e construção, e, consequentemente, a sociedade, a cultura e o direito também estão. Nesse sentido, Bobbio (2004, p. 25) assevera que o direito surge como uma resposta às violências que a sociedade compreende injustificáveis e, desta forma, o desejo é de erradicar como defesa aos abusos de poder. Nas palavras do autor:

[...] os direitos do homem, por mais fundamentais que sejam, são direitos históricos, ou seja, nascidos em certas circunstâncias, caracterizadas por lutas em defesa de novas liberdades contra velhos poderes, e nascidos de modo gradual, não todos de uma vez e nem de uma vez por todas (BOBBIO, 2004, p. 26).

O ponto de partida, para se analisar as etapas históricas da afirmação dos Direitos Humanos, está na compreensão da dignidade humana. Por séculos os povos desenvolveram-se, tendo como fato gerador a indignação com situações impostas à pessoa humana (COMPARATO, 2015, p. 16).

Considera-se que os direitos humanos são comuns a todos os seres humanos, "[...] sem distinção de raça, sexo, classe social, religião, etnia, cidadania política ou julgamento moral" (BENEVIDES, 1994, p. 16), e decorrem do reconhecimento da dignidade intrínseca a todo ser humano. Assim, por direitos humanos entendem-se aqueles direitos considerados fundamentais e que são próprios do homem pelo simples fato de ser humano.

Ao se conceituar os direitos humanos como intrínsecos ao ser humano, encontramos na história da Antiguidade os primeiros resquícios de preocupação com esses direitos para as pessoas. Desta forma, segundo Comparato (2015, p. 20-21), a primeira etapa da afirmação histórica dos direitos humanos foi com o reconhecimento de que as instituições devem ser utilizadas a serviço dos governados e não para o benefício pessoal dos governantes, e exemplifica esse fato por meio da democracia ateniense e da república romana.

Já na era moderna, para Mazzuoli (2002) a Declaração do Bom Povo de Virgínia de 1776 e a Declaração Francesa dos Direitos do Homem e do Cidadão, datada da segunda metade do século 18 (1789), seriam um ponto inicial para a positivação dos direitos humanos, sendo considerados marcos da transição dos direitos de liberdades legais para os direitos fundamentais constitucionais. Já Comparato (2015) afirma que foi com o artigo I da Declaração da Independência Americana que se verificou o registro de nascimento dos Direitos Humanos na história, vindo a consolidar a ideia de igualdade entre os homens, também presente na Declaração do Homem e do Cidadão de 1789 (p. 62). 


\section{Democracia}

Humanos e

Ainda sobre essa construção histórica dos direitos humanos, segundo Bedin (2002, p. 19), nos séculos 17 e 18 firma-se o individualismo. A concepção de que os homens possuem direitos se institucionalizou nesse período, constituindo-se um novo modelo de sociedade. Assim,

Com o surgimento do modelo individualista de sociedade, ocorre uma inversão deôntica: dos deveres para os direitos. É que o modelo individualista de sociedade estabelece um novo centro de articulação política do mundo que possibilita a emergência da idÉia que o homem possui direito a ter direitos. Na verdade, esse novo centro de articulação política é o homem, o indivíduo que se emancipa das estruturas coletivas (...) Por isso, os séculos XVII e XVIII podem ser vistos com um divisor de águas da história da humanidade, pois apresentam-se como o momento em que se firma o individualismo como valor central da sociedade moderna. E o indivíduo como a base do novo modelo de sociedade predominante a partir desse momento (p. 126).

Denota-se que a formação da ideia de direitos dos homens não é tão recente, remontando para alguns autores à Antiguidade; todavia, apesar de não se retirar a importância e fundamentalidade de tais processos históricos, o conteúdo atual de direitos humanos difere desses momentos. O processo recente de internacionalização dos direitos humanos ganhou força com a posterioridade da Segunda Guerra Mundial, sendo esta marco fundamental para indicar parâmetros de uma teoria contemporânea de direitos humanos.

Após as duas grandes guerras mundiais, tornou-se necessário o reconhecimento da Dignidade da Pessoa Humana como uma conquista de razão ético-jurídica. A Declaração Universal dos Direitos Humanos de 1948 tinha, assim, requisito único para a titularidade de direitos e a própria condição humana; a dignidade humana passa a ser incorporada por todos os outros tratados e declarações de direitos humanos que passaram a integrar o Direito Internacional (PIOVESAN, 2013, p. 210).

Sarlet (2009, p. 67), assim como outros autores, concebe a existência de uma dignidade comum a todos os seres humanos, fomentada no respeito e na satisfação de uma série de direitos indispensáveis para a garantia de uma vida digna, o que, consequentemente, justificaria a universalização dos direitos fundamentais.

A dignidade, como valor moral e, também, espiritual, seria um mínimo indispensável de valores que devem ser respeitados pela comunidade, tendo o ser humano o direito a se autodeterminar e liberdade para conduzir sua própria existência, como reconhecimento de sua condição de ser humano.

No século 20, após inúmeras atrocidades e experiências históricas de aniquilação do ser humano vividas na história, principalmente depois das duas grandes guerras mundiais, tornou-se necessário o reconhecimento da Dignidade da Pessoa Humana como uma conquista de razão ético-jurídica. Assim, estes surtos de grandes violências "[...]fazem nascer nas consciências, agora purificadas, a exigência de novas regras de uma vida mais digna para todos" (COMPARATO, 2015, p. 50).

Nessa esteira, diante da reconstrução do mundo moralmente devastado pelo totalitarismo e pelo genocídio, Luís Roberto Barroso (2013) aduz: 
[...] A dignidade humana foi incorporada ao discurso político dos vitoriosos como uma das bases para uma longa e aguardada era de paz, democracia e proteção dos direitos humanos. A dignidade humana foi então importada para o discurso jurídico devido a dois fatores principais. $O$ primeiro deles foi a inclusão em diferentes tratados e documentos internacionais, bem como em diversas constituições nacionais, de referências textuais à dignidade humana. O segundo fator corresponde a um fenômeno mais sutil, que se tornou mais visível com o passar do tempo: a ascensão de uma cultura jurídica, pós-positivista, que reaproximou o direito da moral e da filosofia política, atenuando a separação radical imposta pelo positivismo pré-Segunda Guerra (p. 18).

A Declaração Universal dos Direitos Humanos de 1948, conforme já mencionado, objetivou delinear uma ordem pública fundada no respeito à dignidade humana, e, ao consagrar valores básicos universais, consagrou a dignidade da pessoa. Deste modo, a dignidade humana tornou-se o valor fundante do sistema dos direitos fundamentais e se converteu no patrimônio jurídico-moral da pessoa humana, estampada nos direitos subjetivos incorporados e assegurados pelo sistema constitucional.

A dignidade humana, portanto, constitui uma dimensão normativa. Leciona Bonavides (2001, p. 233), sobre a força normativa deste princípio fundamental, que sua densidade jurídica deve ser máxima, com o princípio de que "[...] todos os ângulos éticos da personalidade se acham consubstanciados".

Nessa esteira, como afirma José Afonso da Silva (2014, p. 107), a dignidade da pessoa humana é um princípio fundamental que inspira a ordem jurídica, uma vez que possui natureza de valor supremo que dimensiona e humaniza a pessoa para a realização e a efetivação dos direitos fundamentais.

Assim, a dignidade da pessoa humana encontra-se no cerne da ordem jurídica brasileira, concebendo a valorização da pessoa humana como sendo razão fundamental para a estrutura de organização do Estado. Considera-se que cada ser humano é igual e possuidor de direitos, independente da circunstância em que nasceu, de sua opção sexual, de sua cultura, religião e governo, pois só depende de sua existência.

Diante dessa exposição, portanto, e não obstante o processo desde a Antiguidade, passando pelas revoluções da era Moderna suprarreferidas, a efetiva consolidação do Direito Internacional dos Direitos Humanos somente aconteceu em meados do século 20, com o advento do final das duas Grandes Guerras Mundiais, em especial da segunda. Foi uma resposta da comunidade internacional às atrocidades perpetradas pelo regime fascista e nazista. Os homens, desta forma, recuam e se horrorizam com suas próprias ações e começam a elaborar novas regras de uma vida mais digna a todos.

Com o findar da Segunda Guerra Mundial, muitas convenções internacionais, dedicadas à matéria de direitos humanos, foram celebradas no âmbito das Organização das Nações Unidas, nas organizações regionais e Organização Internacional do Trabalho.

De acordo com Comparato (2015, p. 69), na seara internacional firmou-se a existência de novas espécies de direitos humanos e os direitos dos povos e da humanidade, a exemplo da Carta Africana dos Direitos Humanos e dos Povos de 1981; nas palavras do autor, com o 


\section{Humanos e}

Democracia

que se concorda plenamente, os direitos humanos ou direitos do homem tratam-se de "[...] algo inerente à própria condição humana, sem ligação com particularidades determinadas de indivíduos ou grupos" (COMPARATO, 2015, p. 71).

O fundamento do direito somente pode ser ancorado em uma consciência ética coletiva e na conviç̧ão da comunidade, em que a dignidade humana exige respeito de certos bens e valores em qualquer circunstância. Logo, os princípios fundamentais do sistema dos direitos humanos são de duas ordens: a dos valores éticos supremos, em que estão inseridas a liberdade, a igualdade e a fraternidade ou solidariedade; e os da ordem da lógica estrutural do conjunto.

\section{DA UNIVERSALIDADE DOS DIREITOS HUMANOS}

Partindo do entendimento de dignidade da pessoa humana como axioma justificante dos direitos humanos, importante se faz trabalhar, mesmo que brevemente, sobre a universalidade de tais direitos.

A Declaração Universal de 1948 trouxe uma inovação no contexto de direitos humanos ao conjugar direitos civis e políticos aos direitos econômicos, culturais e sociais, consolidando a concepção contemporânea de direitos humanos que os define como uma unidade interdependente e indivisível.

Desde o preâmbulo da Declaração dos Direitos Humanos, verifica-se a dignidade como característica inerente a todo o ser humano; o uso de termos como "todos" e "ninguém", por exemplo, demonstra ser em si mesmo universalista, representando a adoção de uma lógica kantiana, com a expansão do imperativo categórico a qualquer pessoa. Ou seja, resgata a ideia kantiana de o homem existir como um fim em si mesmo, com a dignidade independente de qualquer condição, e, assim, o imperativo categórico "age de tal maneira que possa usar a humanidade, tanto em tua pessoa como na pessoa de qualquer outro, sempre e simultaneamente como fim e nunca simplesmente como meio" (KANT, 2011, p. 59).

Ante a universalidade propagada pela Declaração de 48 , houve certa insurgência contra tal pressuposto com a justificativa que a universalidade poderia justificar uma cultura sobre outras, sem considerar suas especificidades, sendo o seu discurso acusado de servir como instrumento ao imperialismo cultural exercido pelas nações hegemônicas ocidentais.

É facilmente perceptível a presença de um caráter individualista na Declaração Universal, conforme expõe Boaventura de Sousa Santos (1997b, p. 113). O documento foi elaborado sem a participação da maioria dos povos do mundo, que se limitou ao reconhecimento, quase com exclusividade, de direitos individuais, com a exceção do direito à autodeterminação, que é coletivo.

Ante a dicotomia universalismo e relativismo, o mesmo autor propõe uma hermenêutica diatópica proposta, que consiste em uma metodologia para o diálogo intercultural que almeja estabelecer condições para que os direitos humanos sejam colocados a serviço de uma política emancipatória (SANTOS, 1997a, p. 30). 
Vale mencionar, ainda na concepção de García (2001, p. 64), com a qual se concorda, de que o ideário individualista não é passível de ser superado, somente relativizado, pois "sin individualismo no hay sujeto de derechos ni derechos". ${ }^{1}$

Do mesmo modo, a origem Ocidental dos Direitos Humanos, por intermédio de eventos importantes, conforme mencionado anteriormente, não o vincula exclusivamente e para sempre. Os direitos do homem refletem, assim, um extenso período de lutas e conquistas, sendo uma aquisição cultural, "[...] relativos em sua nascente, porém universalizáveis na projeção de seu espaço de efetividade" (MELGARÉ, 2002, p. 354).

A tensão entre universalistas e relativistas é uma discussão ainda bem polemizada, principalmente em espaços fortemente marcados pela pluralidade e convivência, como o caso das Américas.

O entendimento que se levanta é a armadilha que o relativismo cultural extremo pode carregar, que está no fato de, ao "[...] afirmarmos a igualdade de direitos de todas as culturas, estaremos incluindo aí aquelas culturas que não admitem que todas têm iguais direitos" (PIACENTINI, 2007, p. 45-46). Assim, a tolerância incondicional abarca, inclusive, as culturas intolerantes, portadoras de práticas culturais ofensivas à dignidade humana.

Há de se considerar, porém, a possibilidade de uma conciliação entre as duas correntes, caso admita-se a existência de gradações de universalismo e relativismo, posto que a definição de cada uma dessas teorias dependerá do espaço que se permite que a cultura ocupe, bem como da extensão do núcleo mínimo de direitos necessários para se assegurar a dignidade como valor universal.

Um documento internacional muito importante é a Declaração e Programa de Ação de Viena - 1993 -, que, segundo Flávia Piovesan, de certa forma tenta conciliar estas duas correntes. Pode-se afirmar que ela acolhe "um relativismo cultural fraco e um forte universalismo" (PIOVESAN, 2013, p. 225), e, em seu parágrafo 5으, estabelece que:

5. Todos os direitos humanos são universais, indivisíveis interdependentes e inter-relacionados. A comunidade internacional deve tratar os direitos humanos de forma global, justa e equitativa, em pé de igualdade e com a mesma ênfase. Embora particularidades nacionais e regionais devam ser levadas em consideração, assim como diversos contextos históricos, culturais e religiosos, é dever dos Estados promover e proteger todos os direitos humanos e liberdades fundamentais, sejam quais forem seus sistemas políticos, econômicos e culturais. ${ }^{2}$

\footnotetext{
García (2001) ainda aduz: "[...] En definitiva, considero que no es demasiado aventurado defender que la concepción individualista occidental y moderna, aunque se trate de una concepción cultural particular en cuanto a la génesis histórica de los derechos, tiene vocación contemporánea de los mismos. Esto no es un tipo de imperialismo cultural, aunque manipulado corre el riesgo de serlo y acompañar a otros tipos de imperialismo, sino el intento de ser mínimamente rigorosos" (p. 64).

2 A Declaração e Programa de Ação de Viena de 1993 está disponível em: http://www.direitoshumanos.usp.br/index.php/ Confer\%C3\%AAncias-de-C\%C3\%BApula-dasNa\%C3\%A7\%C3\%B5es-Unidas-sobre-Direitos-Humanos/declaracao-e-programa-de-acao-de-viena1993.html. Acesso em: 7 jun. 2018.
} 


\section{Humanos e \\ Democracia}

A universalidade seria, desta maneira, enriquecida pela diversidade, que, por sua vez, jamais seria invocada a título de justificar a violação aos direitos humanos, e, conforme Alves (1999, p. 144-145), a Conferência Mundial dos Direitos Humanos, realizada em Viena em 1993, foi o "Maior conclave internacional jamais reunido até então para tratar da matéria", sendo inegável que o consenso alcançado nessa conferência mundial exigiu longas e difíceis negociações, não ocorrendo, porém, propriamente, imposições de parte a parte vencedoras, "nem o documento se propõe violar o âmago de qualquer cultura".

Não se deve deixar de olvidar a incidência da globalização na seara dos direitos humanos, tendo ela destaque tanto nas discussões acerca da diversidade cultural e seu respeito quanto nas políticas e ações intentadas em razão dos direitos humanos.

A crise de legitimidade das políticas de direitos humanos estão diretamente relacionadas com o processo de globalização. Segundo Santos (1997b, p. 105), é importante compreender as tensões da modernidade promovidas pelo processo de globalização, para identificar as condições em que os direitos humanos podem ser postos a serviço de uma política emancipatória. Em suas palavras: "[...] A globalização é o processo pelo qual determinada condição ou entidade local consegue estender a sua influência ao todo globo e, ao fazê-lo, desenvolve a capacidade de designar como local outra condição social ou entidade rival" (SANTOS, 1997b, p. 108).

Nesse viés, García (2001, p. 91-92) leciona que, para tratar de direitos humanos hoje, é preciso contextualizar sua aplicação à sociedade globalizada, sendo necessário, para tanto, que estes se firmem a partir de um conceito de "ética globalizada", identificada como o conjunto de "valores comuns" a todos os seres humanos, pautados na concepção de dignidade humana, liberdade, igualdade e autonomia, cuja pauta não estaria limitada a uma única identidade cultural ou religiosa, sendo, na verdade, "patrimonio de una humanidad civilizada".

Diante da concepção contemporânea dos Direitos Humanos, o que se sustenta é que a partir de determinando momento histórico da humanidade buscou-se cristalizar e desenvolver o ideário de que certas discriminações são inaceitáveis, com base em um consenso construído e pactuado internacionalmente. A contar da Declaração de Direitos Humanos de 1948, inicia-se o desenvolvimento do Direito Internacional dos Direitos Humanos, mediante a adoção de diversos instrumentos internacionais de proteção, seguindo uma ética global orientada pela afirmação da dignidade humana.

\section{OS DIREITOS HUMANOS E AS MULHERES}

A parte inicial do trabalho cristaliza a importância do desenvolvimento dos Direitos Humanos e sua internacionalização, principalmente no que se refere à proteção de direitos dos sujeitos historicamente excluídos dos processos políticos que afirmassem sua igualdade, enquanto ator político, na sociedade.

Quanto à internacionalização de conversão do direito positivo, Bobbio (2004) leciona sobre a nova tendência chamada de especificação, que consiste na passagem gradual para uma ulterior determinação dos sujeitos titulares de direitos. Nos seus dizeres: 
Essa especificação ocorreu com relação seja ao gênero, seja às várias fases da vida, seja à diferença entre estado normal e estados excepcionais na existência humana. Com relação ao gênero, foram cada vez mais reconhecidas as diferenças específicas entre a mulher e o homem. Com relação às várias fases da vida, foram-se progressivamente diferenciando os direitos da infância e da velhice, por um lado, e os do homem adulto, por outro. Com relação aos estados normais e excepcionais, fez-se valer a exigência de reconhecer direitos especiais aos doentes, aos deficientes, aos doentes mentais, etc. (p. 79).

O que se verifica é que a primeira fase de proteção dos direitos humanos foi marcada pela tônica da proteção geral e abstrata, com base na igualdade formal. Agora, na contemporaneidade, é insuficiente tratar o indivíduo de forma geral e abstrata, sendo necessária a especificação do sujeito de direito.

Assim, diante da formação atual dos Direitos Humano, no que se refere à garantia dos direitos humanos das mulheres, a adoção de um parâmetro universalista, ainda que com um amplo espaço para relativismos culturais, é de grande importância, tendo em vista o quadro de violência e violações em relação à mulher ser muito expressivo, principalmente no que concerne às graves obstruções à fruição de seus direitos, justificadas com base em práticas culturais historicamente definidas.

Apesar de não se escusar das dificuldades da perspectiva universalista, entende-se importante utilizá-la como ponto de chegada; um universalismo de confluência. Neste sentido, o que se nega é "[...] considerar o universal como ponto de partida ou campo de desencontros. Ao universal há que se chegar - universalismo de chegada ou de confluência - depois (não antes de) um processo conflitivo, discursivo de diálogo" (FLORES, 2002, p. 7).

Visa-se, assim, a assegurar a dignidade de grupo de vulneráveis a partir da especificação do sujeito de direito, que passa a ser visto em sua peculiaridade e particularidade. A exemplo dessa categoria de vulneráveis, que devem ser tratados de acordo com suas especificidades, estão as mulheres, as crianças, os indivíduos com deficiência, os refugiados, dentre outros.

Importa afirmar que o direito à diferença implica o direito ao reconhecimento de identidades próprias, o que propicia a incorporação da perspectiva de gênero, ou seja, repensar os direitos humanos a partir da relação entre os gêneros, como um tema transversal. As normas de proteção aos direitos humanos, em seu processo de desenvolvimento, reflete a participação do movimento feminista em reivindicações como a igualdade formal e econômica, a liberdade reprodutiva e sexual, e o direito à diversidade sexual, racial e étnica.

Para Piovesan (2012, p. 7), essas reivindicações foram incorporadas pelos tratados internacionais de proteção aos direitos humanos, posto que, ao se realizar um balanço das últimas décadas, constata-se que o movimento internacional de proteção aos direitos humanos das mulheres teve como foco três conteúdos centrais, que seriam: a discriminação contra a muIher; a violência contra a mulher e os direitos sexuais e reprodutivos.

A contribuição dos tratados internacionais de proteção a direitos humanos, em especial aos direitos humanos das mulheres, contribui de forma expressiva para a promoção das liberdades e o acesso a condições igualitárias de desenvolvimento social. O desenvolvimento de muitos países está correlatamente ligado ao ganho de poder das mulheres, que transparece em fatores como a educação, seu padrão de propriedade, as oportunidades de emprego às quais elas têm acesso e o funcionamento do mercado de trabalho (SEN, 2000, p. 234-235). 


\section{Humanos e \\ Democracia}

A realidade social de desigualdades das mulheres é promovida, ainda, pela ausência de uma cultura jurídica sobre os direitos humanos das mulheres, sendo imperiosa a promoção de estudos dos problemas dela originados, tendo em vista que muitos Estados insistem em normas que estabelecem uma discriminação tanto econômica quanto contra a mulher.

Assim, quais medidas que têm sido instituídas com o objetivo de acabar com as situações discriminatórias associadas ao gênero contra a mulher? Quais são os Estados empenhados em tornar efetiva a igualdade entre homens e mulheres? Qual tem sido o seu resultado alcançado? Como solucionar a situação de desigualdade e violência a partir do Direito? Quais os instrumentos jurídicos existentes no âmbito internacional para lutar contra a discriminação?

A aceitação, tolerância e perpetração de violência de gênero, além de um sintoma de uma clara ausência de igualdade, é uma questão universal que transcende estereótipos culturais, classes sociais, nível de renda, formação acadêmica, idade, religião ou etnia. Alcançar a igualdade real e eficaz entre mulheres e homens é uma questão de direitos humanos, de justiça e de desenvolvimento social e econômico, político e social. Alcançar essa igualdade também é um requisito essencial para acabar com a violência de gênero, um problema público e uma injustiça social que questiona os princípios democráticos de um Estado.

Essas são questões que devem ser suscitadas cada vez mais na seara internacional. Desta feita, o próximo tópico busca analisar, de forma geral, os instrumentos jurídicos internacionais que garantem os direitos das mulheres.

O que se constata é a insuficiência do sistema internacional dos direitos humanos em dar respostas efetivas e adequadas à especificidade dos problemas e das necessidades de um grupo vulnerável como o das mulheres. A legislação protetora, ainda, é insuficiente para os fins aos quais deveria prestar, mascarando a violência existente, tendo em vista a tendência de se criar soluções de caráter imediato para o problema, que desvaloriza as formas de violência visualmente invisíveis, e que, de algum modo, mantém o reconhecimento dessas situações de desrespeito aos seus direitos como afetas apenas ao âmbito privado.

O próximo subitem irá abordar os instrumentos de proteção internacional dos direitos das mulheres, em que se faz uma retrospectiva de tais documentos e sua importância na busca de uma efetividade dos direitos humanos.

\subsection{Dos instrumentos de proteção internacionais dos direitos das mulheres}

As Nações Unidas é uma das organizações internacionais que mais deu impulso à perspectiva de gênero. A Carta das Nações Unidas inclui, no seu preâmbulo, o princípio de igualdade entre homens e mulheres, sendo reforçado e alargado, pelo que veio a ser chamado de Carta Internacional de Direitos Humanos, em referência à Declaração Universal dos Direitos do Homem, ao Pacto Internacional sobre os Direitos Civis e Políticos e ao Pacto Internacional sobre os Direitos Econômicos, Sociais e Culturais.

O ponto de arranque no processo de proteção dos direitos humanos das mulheres em âmbito internacional e, mais concretamente, no reconhecimento formal da igualdade da muIher, pode ser situado na Declaração sobre a Eliminação da Discriminação Contra as Mulheres, 
adotada pela Assembleia Geral da ONU em 1967. Vale mencionar, porém, que a declaração foi apenas um mero compromisso político entre os Estados sem força vinculativa, e, segundo Yolanda Gómez Lugo (2014, p. 150), observa:

[...] apesar do reconhecimento da igualdade formal nos diferentes tratados e convenções sobre direitos humanos, a prática evidencia uma desigualdade real entre o gênero masculino e o gênero feminino, situação que requer um tratamento definitivo que incorpore a perspectiva de gênero no sistema internacional de proteção de direitos.

Fica de fácil notoriedade que as mulheres continuam a formar um grupo particularmente vulnerável por razão de gênero, como evidenciado nas constantes transgressões que sofrem dos seus direitos. Apesar de se constituir uma previsão universal, "o ultraje à dignidade e aos direitos da mulher continua sendo uma constante, demonstrando a dificuldade de algumas sociedades em reconhecer o sexo feminino no mesmo patamar ocupado pelo masculino e em vislumbrar a mulher como sujeito de direitos, livre, capaz e igual aos homens" (COSTA; SOUZA; CHAGAS, 2013, p. 148).

Levanta-se a situação de grande desigualdade presente na América Latina e a essencial importância de os Estados assumirem um compromisso com a garantia e a plena consolidação dos direitos econômicos, sociais e culturais. Nesse sentido, Tamara Amoroso Gonçalves (2013, p. 90) assevera que, com relação às mulheres especificamente, a não efetividade da fruição dos direitos socioseconômicos pode significar obstruções ao pleno acesso à saúde e à educação, dentre outros importantes direitos, corroborando situações de violação, integridade e dignidade.

A mesma autora aborda, em seu estudo, o status da litigância em direitos humanos das mulheres na América Latina, a partir da análise da atuação da Comissão Interamericana de Direitos Humanos no período de 1970 a 2008, e constata que os posicionamentos adotados pela Comissão são favoráveis aos direitos humanos das mulheres, podendo e devendo servir de substrato para a exigibilidade do cumprimento destes direitos. Nos dizeres da autora:

[...] na medida em que contribuem para enfrentar os desafios que ainda se colocam para o pleno reconhecimento das mulheres como sujeitos de direitos e atores sociais. Também buscam a incorporação de novas temáticas para a pauta dos direitos humanos na região, arejando o próprio conceito destes direitos, alargando os limites de sua definição (GONÇALVES, 2013, p. 299).

Nesta ocasião, ressalta-se ser necessário um debate público, trazido pelo litígio estratégico internacional na perspectiva de gênero, que força uma reflexão da sociedade sobre as assimetrias de poder e desigualdades enfrentadas pelas mulheres. O potencial transformador desta litigância permite a visibilidade de temáticas que nem sempre encontram espaço nas arenas públicas de debates, bem como um novo olhar para os direitos humanos tradicionalmente estabelecidos.

Um outro importante documento de combate à violência contra a mulher no âmbito internacional, é a Convenção sobre a Eliminação de todas as formas de Discriminação contra a Mulher aprovada em 1979 pela Assembleia Geral, em vigor desde 1981, de amplo grau de adesão, porém, infelizmente, com grande número de reservas por parte de muitos Estados signatários. 


\section{Humanos e \\ Democracia}

O artigo 28 da Convenção admite a possibilidade de que os Estados Partes formulem reservas ao tratado no momento da ratificação ou adesão, apesar de o artigo 28.2 estabelecer um limite a esse poder, ao prever que não serão autorizadas as reservas incompatíveis com o objeto e fim da Convenção.

Referente às reservas, Piovesan (2012, p. 76) afirma:

Trata-se do instrumento internacional que mais fortemente recebeu reservas, dentre as Convenções internacionais de Direitos Humanos, considerando que ao menos 23 dos mais de 100 Estados-partes fizeram, no total, 88 reservas substanciais. A Convenção sobre a Eliminação de todas as formas de Discriminação da Mulher pode enfrentar o paradoxo de ter maximizado sua aplicação universal ao custo de ter comprometido sua integridade. Por vezes, a questão legal acerca das reservas feitas à Convenção atinge a essência dos valores da universalidade e integridade.

A preocupação generalizada sobre o problema das reservas levou a que os Estados Partes se comprometessem, na Plataforma de Ação de Pequim, não apenas à ratificação universal da Convenção em 2000, mas também em limitar o alcance das reservas à mesma, garantindo que nenhuma fosse incompatível com o objeto e fim do Tratado.

A Carta sobre a Eliminação de todas as formas de Discriminação contra a Mulher foi resultado das reivindicações do movimento de mulheres, a partir da primeira Conferência Mundial sobre a Mulher, realizada no México, em 1975. Trata-se de uma Convenção de direitos das mulheres, que abrange seus direitos civis, políticos, econômicos, sociais e culturais.

A discriminação contra a mulher é definida na Convenção como qualquer distinção, exclusão ou restrição baseada no sexo, que tenha por objeto anular o reconhecimento, o gozo ou o exercício de direitos humanos ou liberdades fundamentais pelas mulheres. A temática não foi abordada com tanta clareza no documento internacional, tendo sido o tema mais bem trabalhado na Recomendação Geral n. 19, que expressamente declara que "a violência baseada no gênero é uma forma de discriminação que compromete seriamente a capacidade das mulheres de gozarem de seus direitos e liberdades em um patamar de equidade em relação aos homens". ${ }^{3}$

Assim, a Convenção foi um marco de real importância internacional, cujo objetivo é promover a plena igualdade entre homens e mulheres num mundo baseado na equidade e na justiça. Diante dessa perspectiva, enfatiza-se que, apesar de ser um texto que representa um progresso na luta contra a discriminação, o documento não é uma ferramenta de reconhecimento de direitos humanos novos, mas, sim, de promoção dos existentes nesse momento.

Existe um certo progresso no que se refere à consolidação da Convenção no sistema universal de proteção dos direitos humanos, e isso se deve ao nível de monitoramento e controle previstos. Sobre a temática, Eva Díez Peralta (2011) assevera:

\footnotetext{
COMITÊ SOBRE A ELIMINAÇÃO DA DISCRIMINAÇÃO CONTRA AS MULHERES. Violence against women. CEDAW General Recommendation 19, A/47/38. (General Comments), 29/1/92, parágrafo 1o. Disponível em: http://www.unhchr.ch/tbs/ doc.nsf/0/300395546e0dec52c12563ee0063dc9d? Opendocument. Acesso em: 10 jun. 2018.
} 
Donde sí se puede afirmar que se ha producido algún progreso que consolida la posición de esta Convención en el sistema universal de protección de los derechos humanos es en el plano del seguimiento y control. En un primer momento, el mecanismo de control del cumplimiento por parte de los Estados partes de las obligaciones contraídas en virtud de la Convención estaba basado, tan sólo, en la elaboración de informes periódicos dirigidos, cada cuatro años, al Comité para el examen de las medidas legislativas, judiciales, administrativas o de otra índole que aquellos adoptan en sus respectivos ordenamientos internos (p. 103).

Como bem alerta a autora supramencionada, porém, esses relatórios periódicos muitas vezes não promovem autocrítica, de modo que os Estados se limitam, em grande parte, a reproduzir disposições constitucionais ou legais na matéria, constituindo um verdadeiro obstáculo à satisfação total e da Convenção.

Ainda sobre o órgão de controle sobre a aplicação da mesma, denominado Comitê para a Eliminação da Discriminação Contra as Mulheres, na prática o funcionamento deste mostrou-se ineficaz, pelo menos inicialmente, e isso deve-se, principalmente, à ausência de um mecanismo de impugnação, tendo em vista a carência de instrumentos ou processos que permitam um recurso às vítimas das violações de direitos humanos internacionalmente reconhecidos.

Desta forma, em 1999, com o objetivo de combater essa deficiência, foi adotado o Protocolo Facultativo à Convenção. ${ }^{4}$ Este criou dois mecanismos de participação novos: o procedimento de denúncia individual e o procedimento de investigação. O primeiro consiste no desenvolvimento de "comunicações" ou demandas individuais por pessoas, ou grupos de pessoas, sobre a violação dos direitos reconhecidos na Convenção por parte de um Estado Parte que aceite a competência do Comitê. O segundo procedimento consiste no pedido de uma investigação sobre uma violação grave ou sistêmica dos direitos humanos das mulheres por parte de um Estado Parte, embora, neste caso, o Protocolo permita aos Estados não acoIher este procedimento de investigação se, assim, o manifestarem no momento da assinatura ou ratificação.

Realça-se, desta forma, a importância do protocolo supramencionado na efetivação da Convenção em âmbito internacional. Nesse sentido, afirma Lugo (2014, p. 160) que o Protocolo é uma ferramenta essencial para o estabelecimento da Convenção que permite promover a reparação às vítimas.

Com a IV Conferência das Nações Unidas sobre as Mulheres, de Pequim em 1995, instaura-se uma nova fase no processo de proteção dos direitos humanos das mulheres em âmbito internacional, representando um progresso no objetivo de conseguir a igualdade real entre homens e mulheres e eliminar a discriminação pelo gênero.

A grande novidade da IV Conferência mundial foi apresentar a incorporação da perspectiva de gênero ao contexto das Nações Unidas. Essa abordagem foi impulsionada por essa Conferência com o objetivo de instituição políticas públicas inspiradas no princípio de igualdade e de não discriminação entre o gênero masculino e o feminino (LUGO, 2014, p. 165). Ainda sobre a Conferência: 


\section{Humanos e}

Democracia

En esta conferencia se planteaban una pregunta clave “¿Cómo podemos modificar esta estructura?" Al intentar responderla descubrieron la necesidad de centrar los esfuerzos no ya en promover políticas de Igualdad centradas exclusivamente en la Mujer sino políticas con perspectiva de género, sustituyendo el tratamiento aislado de la cuestión por un tratamiento integral, incluido en el conjunto de las políticas, reafirmando los Derechos de la Mujer como Derechos Humanos (LÓPEZ-FRANCÉS; VIANA-ORTA, 2015, p. 204).

Como resultado desta Conferência, a Declaração e Plataforma de Ação foi adotada de Pequim, com um Programa que inclui 12 áreas de preocupação especial que constituem um obstáculo para alcançar a igualdade entre mulheres e homens. A educação é uma destas 12 áreas. Desde esta declaração, os governos e a sociedade civil têm sido obrigados a incluir uma perspectiva de gênero (mainstreaming) em todas as suas instituições políticas, processos de planejamento e tomadas de decisão.

Seguindo a análise dos instrumentos internacionais sobre os direitos humanos das muIheres, outro que não se pode deixar de olvidar é a Convenção Interamericana para Prevenir, Punir e Erradicar a Violência contra a Mulher, conhecida como Convenção de Belém do Pará, adotada pela Assembleia Geral da Organização dos Estados Americanos em 6 de junho de 1994 e ratificada pelo Brasil em 27 de novembro de 1995. Este tratado reconhece que a violência contra a mulher, no âmbito público ou privado, constitui grave violação aos direitos humanos e limita total ou parcialmente o exercício dos demais direitos fundamentais.

Esta Convenção elenca um importante catálogo de direitos a ser assegurado às mulheres, para que tenham uma vida livre de violência, e consagra ainda, a Convenção, deveres aos Estados-partes, para que adotem políticas destinadas a prevenir, punir e erradicar a violência contra a mulher.

Sobre a Convenção de Belém do Pará, Piovesan (2012, p. 79) aduz que "É o primeiro tratado internacional de proteção dos direitos humanos a reconhecer, de forma enfática, a violência contra as mulheres como um fenômeno generalizado [...]". Ainda, nesse raciocínio:

A convenção afirma que a violência contra a mulher constitui grave violação aos direitos humanos e limita total ou parcialmente o exercício dos demais direitos fundamentais. Adiciona que a violência contra a mulher constitui ofensa à dignidade humana, sendo manifestação de relações de poder historicamente desiguais entre homens e mulheres (LEOPOLDI; TELES; GONZAGA, 2007, p. 16).

Ao reconhecer a situação de vulnerabilidade das mulheres, a Convenção de Belém do Pará Ihes garante um significativo rol de direitos a serem protegidos. Entre eles, tem-se o direito à integridade física, mental e psicológica, o direito de não ser submetida à tortura e o direito de liberdade e segurança pessoais.

O artigo 3으 da Convenção garante à mulher uma vida livre de violência, tanto no âmbito público quanto no privado; complementando-o, tem-se o artigo 6으, que dispõe que uma vida livre de violência inclui (a) o direito de ser livre de toda forma de discriminação e (b) o direito de ser valorizada e educada livre de padrões estereotipados de comportamento e práticas sociais e culturais baseados em conceitos de inferioridade de subordinação. Desta forma, ao se analisar a Convenção extrai-se o objetivo dela em alterar a estrutura patriarcal da sociedade, incentivando as mudanças culturais e reprimindo discriminações. 
Após o estudo feito até o momento, pode se verificar que a violência contra a mulher é definida como um fenômeno histórico-social, resultado de relações de poder desiguais, que transcende a diferença de renda, das classes sociais e culturais, uma realidade que deve ser abordada de forma holística para erradicá-lo.

O que se pode constatar da análise feita anteriormente, é que existe um amplo quadro legislativo normativo internacional sobre a igualdade entre mulheres e homens, e a não discriminação por razões de gênero é um princípio legal valorizado universalmente, reconhecido por tratados internacionais de acordo com a Declaração dos Direitos Humanos, bem como nas leis da maioria dos países.

Ainda, porém, existem desigualdades, discriminação, violência e injustiça contra as muIheres que mostram que a igualdade efetiva continua sendo uma tarefa pendente, sendo portanto, neste contexto, a dignidade e a possiblidade de uma vida digna constantemente violadas.

Assim, é visível que a simples mudança de leis não necessariamente significa uma transformação de comportamentos e de percepções no que se refere a papéis de gênero tradicionalmente estabelecidos. O necessário debate público trazido pelo litígio estratégico internacional na perspectiva de gênero, portanto, força uma reflexão da sociedade sobre as assimetrias de poder e desigualdades enfrentadas pelas mulheres.

\section{CONSIDERAÇÕES FINAIS}

Uma sociedade de multiplicidades e pluralidade social, onde convive uma gama de grupos heterogêneos, não deve ter espaço para a discriminação, sexismo e violação de direitos básicos do homem.

Constatou-se, no estudo, que as mulheres formam um grupo particularmente vulnerável por razão de gênero, como evidenciado nas constantes transgressões que sofrem dos seus direitos. Apesar de se constituir uma previsão universal, a violação à dignidade e aos direitos da mulher continua sendo uma constante, demonstrando a dificuldade de algumas sociedades em reconhecer o sexo feminino no mesmo patamar ocupado pelo masculino, e em vislumbrar a mulher como sujeito de direitos, livre, capaz e igual aos homens.

Diante desse cenário, o problema do presente estudo consistia em ofertar maior visibilidade às mulheres e aos seus direitos. Desta forma, buscou expor e analisar, a partir da dignidade da pessoa humana como palavra de ordem, os direitos humanos, sua evolução histórica e seu caráter universal.

No que diz respeito à garantia dos direitos humanos das mulheres, a adoção de um parâmetro universalista, ainda que com um amplo espaço para relativismos culturais, é de grande importância, levando em consideração o quadro de violência e violações em relação à mulher ser, ainda, muito expressivo, principalmente no que se refere ás graves obstruções à fruição de seus direitos. Assim, apesar de não se escusar das dificuldades da perspectiva universalista, entende-se importante utilizá-la como ponto de chegada; um universalismo de confluência.

O estudo ficou claro pela análise histórica dos direitos humanos, que, a partir de determinando momento histórico da humanidade, buscou cristalizar e desenvolver o ideário de que certas discriminações são inaceitáveis, com base em um consenso construído e pactuado 


\section{Democracia}

Humanos e

internacionalmente. Levanta-se a essencial importância da Declaração de Direitos Humanos de 1948, e que a partir dela se iniciou o desenvolvimento do Direito Internacional dos Direitos Humanos, mediante a adoção de diversos instrumentos internacionais de proteção, seguindo uma ética global orientada pela afirmação da dignidade da pessoa humana.

Buscou-se, assim, enfatizar a importância do desenvolvimento dos Direitos Humanos e sua internacionalização, principalmente quanto à proteção de direitos dos sujeitos historicamente excluídos dos processos políticos que afirmassem sua igualdade enquanto ator político na sociedade, e extrair os diversos instrumentos que tratam da proteção dos direitos humanos da mulher. Nesta oportunidade, a contribuição dos tratados internacionais de proteção a direitos humanos, em especial aos direitos humanos das mulheres, contribui, de forma expressiva, para a promoção das liberdades e o acesso a condições igualitárias de desenvolvimento social.

Ainda, constatou-se que a aplicação efetiva deste contexto normativo necessita da atuação por parte das autoridades públicas, por meio de medidas de carácter legislativo e/ ou institucional. Não é suficiente, no entanto, o reconhecimento normativo de um sistema de proteção jurídica dos direitos humanos; é necessário que este processo seja aceito pela sociedade, ou seja, que seja acompanhado por uma mudança de atitude e de comportamento por parte dos membros da sociedade, de forma a criar as condições idôneas para a consolidação do mesmo, e acabar com os estereótipos socioculturais de conduta baseados na inferioridade da mulher.

É preciso, portanto, um novo olhar para os direitos humanos tradicionalmente estabelecidos; um olhar que inclui a mulher e as suas especificidades, conformadas em um processo histórico construído desigualmente na pauta dos direitos humanos, que evidencia as construções assimétricas de poder e, como tal, afeta desproporcionalmente homens e mulheres.

\section{REFERÊNCIAS}

ALVES, J. A. Lindgren. A declaração dos direitos humanos na pós-modernidade. In: BOCAULT, Carlos Eduardo de Abreu; ARAUJO, Nadia de (org.). Os direitos humanos e o direito internacional. Rio de Janeiro: Renovar, 1999.

BARROSO, Luís Roberto. A dignidade da pessoa humana no Direito Constitucional Contemporâneo: a construção de um conceito jurídico à luz da jurisprudência mundial. Belo Horizonte: Fórum, 2013.

BEDIN, Gilmar Antônio. Os direitos do homem e o neoliberalismo. 3. ed. Ijuí: Editora Unijuí, 2002.

BENEVIDES, Maria Victória. Cidadania e justiça. In: Revista da FDE, São Paulo, n. 33, ago. 1994. Disponível em: https://www.scielo.br/scielo.php?script=sci_arttext\&pid=S0102-64451994000200002\&lng=pt\&tlng=pt.

BOBBIO, Norberto. A era dos direitos. Rio de Janeiro: Elsevier, 2004.

BONAVIDES, Paulo. Teoria Constitucional da Democracia Participativa: por um Direito Constitucional de luta e resistência, por uma Nova Hermenêutica, por uma repolitização da legitimidade. São Paulo: Malheiros Editores, 2001.

CALDERÓN-VALENCIA, Felipe; ESCOBAR-SIERRA, Manuela. L'articulation de la juridiction spéciale pour la paix avec la justice ordinaire en matière d'extradition: les enjeux politiques du cas Jesus Santrich dans le contexte du post-conflit Colombien. Revista Direitos Sociais e Políticas Públicas - Unifafibe, v. 7, n. 1, 2019.

CIARLINI, Léa Martins Sales; CIARLINI, Alvaro Luis de Araujo. A estrutura das políticas públicas e os paradoxos da intervenção judicial por meio da ação civil pública: uma análise a partir dos cinco estágios do ciclo político-administrativo de Michael Howlett, Ramesh e Perl. Revista Direitos Sociais e Políticas Públicas - Unifafibe, v. 7, n. 1, 2019.

COMITÊ SOBRE A ELIMINAÇÃO DA DISCRIMINAÇÃO CONTRA AS MULHERES. Violence against women. CEDAW General Recommendation 19, A/47/38. (General Comments), 29/1/92, parágrafo 1‥ Disponível em: http://www. unhchr.ch/tbs/doc.nsf/0/300395546e0dec52c12563ee0063dc9d?Opendocument. Acesso em: 10 jun.2018. 
COMPARATO, Fabio Konder. A afirmação histórica dos direitos humanos. 9. ed. São Paulo: Saraiva, 2015.

COSTA, Andréia da Silva; SOUZA, Lucas Martins Pessoa Eugênio de; CHAGAS, Márcia Correa. Convenção Interamericana Para Prevenir, Punir e Erradicar a Violência Contra a Mulher: Convenção de Belém do Pará. In: LOPES, Ana Maria D'Ávila; JUCÁ, Roberta Laena Costa; COSTA, Andréia da Silva (org.). Gênero e tráfico de mulheres. Florianópolis: Editorial Conceito, 2013. Disponível em: https://s3.amazonaws.com/academia.edu.documents/52111938/Genero_e_Trafico_de_Mulheres_01_1_.pdf?AWSAccessKeyld=AKIAIWOWYYGZ2Y53UL3A\&EXpires1530538439\&Signature $=x x 10464 \mathrm{PY} \% 2 \mathrm{~B} 5 \mathrm{Bb} 8 \mathrm{Na} 7 \mathrm{r} 6 \mathrm{hJ} 8 \mathrm{YW}$ 9IE\%3D\& responsecontentdisposition=in line\%3B\%20filename\%3DGENERO_E_TRAFICO_DE_MULHERES.pdf\#page=147. Acesso em: 2 jul. 2018.

FERREIRA, Olavo Augusto Vianna Alves; LEHFELD, Lucas de Souza; SIQUEIRA, Dirceu Pereira. A imunidade parlamentar segundo o supremo tribunal: análise do precedente sobre a prisão do senador Delcídio Amaral frente aos direitos da personalidade. Revista Direitos Sociais e Políticas Públicas - Unifafibe, v. 7, n. 2, 2019.

FLORES, Joaquin Herrera. Direitos humanos, interculturalidade e racionalidade de resistência. Seqüência: Estudos Jurídicos e Políticos, Florianópolis, p. 9-30, jan. 2002. ISSN 2177-7055. Disponível em: https://periodicos.ufsc. br/index.php/sequencia/article/view/15330. Acesso em: 8 jul. 2018.

FLORIANI, Lara Bonemer Rocha; SANTOS, Luccas Farias. A hierarquia dos tratados internacionais e seus reflexos jurídicos e extrajurídicos. Revista Direitos Sociais e Políticas Públicas - Unifafibe, v. 7, n. 1, 2019.

GARCíA, Eusebio Fernández. Dignidad Humana y Ciudadanía Cosmopolita. Cuadernos Bartolomé de las Casas, Madrid: Dykinson, n. 21, 2001.

GONÇALVES, Tamara Amoroso. Direitos Humanos das Mulheres e a Comissão Interamericana de Direitos Humanos. São Paulo: Saraiva, 2013.

KANT, Immanuel. Fundamentação da metafísica dos costumes e outros escritos. Tradução Leopoldo Holzbach. São Paulo: Martin Claret, 2011.

LASCANO, Alfonso Jaime Martinez. Inconvencionalidad del amparo mexicano por la eficacia en la protección judicial de derechos humanos. Revista Direitos Sociais e Políticas Públicas - Unifafibe, v. 7, n. 2, 2019.

LEOPOLDI, Deisi; TELES, Maria Amélia de Almeida; GONZAGA, Terezinha de Oliveira. Do silêncio ao grito contra a impunidade: caso Márcia Leopoldi. São Paulo: União das Mulheres de São Paulo, 2007.

LÓPEZ-FRANCÉS, Inmaculada; VIANA-ORTA, Maria Isabel. La igualdad de género: un derecho humano vulnerado. Revista Interdisciplinar de Direitos Humanos, Bauru, n. 4, p. 199-209, jun. 2015.

LUGO, Yolanda Gómez. Sistema internacional de proteção dos direitos humanos das mulheres. In: BELTRÃO, Jane Felipe et al. Direitos humanos dos grupos vulneráveis. Manual. Rede Direitos Humanos e Educação Superior, 2014. p. 145-170. Disponivel em: dhes-alfa>materials>. Acesso em: 17 maio 2016.

MABTUM, Matheus Massaro; GERRA FILHO, Willis Santiago. A importância do tempo e sentido para a teoria dos sistemas de Niklas Luhmann. Revista Direitos Sociais e Políticas Públicas - Unifafibe, v. 6, n. 2, 2018.

MAZZUOLI, Valerio de Oliveira. Direitos humanos e cidadania à luz do novo direito internacional. Campinas: Minelli, 2002.

MELGARÉ, Plínio. Direitos humanos: uma perspectiva contemporânea para além dos reducionismos tradicionais. Revista Ajuris, Porto Alegre, n. 88, p. 331-360, dezembro/2002.

OLIVEIRA, Cleberson Cardoso de. O direito à saúde aos pacientes conforme a Constituição da República de 1988. Revista Direitos Sociais e Políticas Públicas - Unifafibe, v. 3, n. 1, 2015.

PERALTA, Eva Díez. Los Derechos de la Mujer en el Derecho Internacional. Revista Española de Derecho interNacional, Madrid, v. 63, n. 2, jul./dic. 2011. ISSN 0034-9380.

PIACENTINI, Dulce de Queiroz. Direitos humanos e interculturalismo: análise da prática cultural da mutilação genital feminina. 2007. Dissertação (Mestrado) - Universidade Federal de Santa Catarina, Centro de Ciências Jurídicas, Programa de Pós-Graduação em Direito, Florianópolis, SC, 2007.

PIOVESAN, Flávia. A Proteção Internacional dos Direitos Humanos das Mulheres. Revista da EMERJ, v. 15, p. 7089, 2012.

PIOVESAN, Flávia. Direitos humanos e o direito constitucional internacional. 14. ed. São Paulo: Saraiva, 2013.

RODRIGUEZ HUERTA, G. La no discriminación de las mujeres: objeto y fin de la CEDAW. In: VAZQUEZ, R.; CRUZ PARCERO, J. (coord.). Derechos de las mujeres en el derecho internacional. Tomo 1, Serie Género, Derecho y Justicia. México: SCJN-Fontamara, 2010.

ROSSIGNOLI, Marisa; SOUZA, Francielle Calegari de. O princípio constitucional da livre concorrência frente a política do desenvolvimento sustentável. Revista Direitos Sociais e Políticas Públicas - Unifafibe, v. 7, n. 1, 2019. 


\section{Humanos e \\ Democracia}

SANTOS, Boaventura de Sousa. Por uma concepção multicultural de direitos humanos. Revista Crítica de Ciências Sociais, n. 48, 1997a. Disponível em: http://www.boaventuradesousasantos.pt/media/pdfs/Concepcao_multicultural_direitos_humanos_RCCS48.PDF. Acesso em: 3 set. 2016.

SANTOS, Boaventura de Sousa. Uma concepção multicultural de direitos humanos. Revista Lua Nova, n. 39, 1997b.

SARLET, Ingo Wolfgang. Dignidade da pessoa humana e direitos fundamentais na Constituição Federal de 1988. 7. ed. Porto Alegre: Livraria do Advogado, 2009.

SEN, Amartya. Desenvolvimento como liberdade. São Paulo: Companhia das Letras, 2000.

SILVA, José Afonso da. Direito Constitucional Positivo. 37. ed. São Paulo: Malheiros, 2014

SIQUEIRA, Dirceu Pereira; FERRARI, Caroline Clariano. O direito à informação como direito fundamental ao estado democrático. Revista Direitos Sociais e Políticas Públicas - Unifafibe, v. 4, n. 2, 2016.

SIQUEIRA, Dirceu Pereira; CASTRO, Lorenna Roberta Barbosa. Minorias e grupos vulneráveis: a questão terminológica como fator preponderante para uma real inclusão social. Revista Direitos Sociais e Políticas Públicas - Unifafibe, v. 5, n. 1, 2017.

SIQUEIRA, Dirceu Pereira; GOTTEMS, Claudinei J. Direitos fundamentais: da normatização à efetividade nos 20 anos de Constituição brasileira. Birigui: Boreal, 2008.

SIQUEIRA, Dirceu Pereira; PICCIRILO, Miguel Belinati. Inclusão social e direitos fundamentais. Birigui: Boreal, 2009.

SIQUEIRA, Dirceu Pereira; JÚNIOR, Teófilo Marcelo de Arêa Leão (org.). Direitos sociais: uma abordagem quanto à (in)efetividade desses direitos - a Constituição de 1988 e suas previsões sociais. Birigui: Boreal, 2011.

SOARES, Marcelo Negri; KAUFFMAN, Marcos Eduardo; MARTIN, Raphael Farias. Economy law and economic analysis of law and the impacto on intellectual property in the common law system. Revista Direitos Sociais $e$ Políticas Públicas - Unifafibe, v. 7, n. 2, 2019.

STURZA, Janaína Machado; RODRIGUES, Bruna dos Passos. Diálogos entre políticas públicas e direito à saúde: as audiências públicas enquanto instrumento de participação popular sob a perspectiva da teoria da ação comunicativa de Habermas. Revista Direitos Sociais e Políticas Públicas - Unifafibe, v. 7, n. 2, 2019.

ZEIFERT, Anna Paula Bagetti. Pensar as políticas públicas a partir do enfoque das capacidades: justiça social e respeito aos direitos humanos. Revista Direitos Sociais e Políticas Públicas - Unifafibe, v. 7, n. 1, 2019. 